\title{
CRIPPLING TEST OF A BUDD M-1 PASSENGER RAILCAR: TEST AND ANALYSIS RESULTS
}

\author{
Michael Carolan \\ Benjamin Perlman \\ David Tyrell \\ Volpe National Transportation Systems Center \\ US Department of Transportation \\ Cambridge, MA 02142 \\ www.volpe.dot.gov
}

\author{
Jeff Gordon \\ Federal Railroad Administration \\ Office of Research and Development \\ US Department of Transportation \\ Cambridge, MA 02142 \\ www.fra.dot.gov
}

\section{ABSTRACT}

The Federal Railroad Administration's (FRA) Office of Research and Development is conducting research into the occupied volume integrity (OVI) of passenger railcars. OVI refers to a passenger railcar's ability to preserve space for passengers and crew during accident loading conditions. The information developed in this research program will form the basis for establishing alternative OVI evaluation procedures. These alternative procedures, in turn, will allow a wider variety of passenger railcar designs to have their OVI evaluated, will provide guidance for applying modern engineering technologies, such as finite element analysis (FEA), and will continue to ensure a level of safety in evaluated vehicles equivalent to conventional evaluation.

As part of this research program, two tests and corresponding FEA were conducted on a Budd M-1 passenger railcar that had been retrofitted with crash energy management (CEM) components on both ends. This testing and analysis program was sponsored by FRA and carried out by Transportation Technology Center, Inc. (TTCI), Arup, and the Volpe Center. An 800,000 pound load test was conducted on March 13, 2013 and was intended to elastically deform the car. The data generated during this test were, in turn, used to validate FE models of the M-1 car. The second test was performed on July 17, 2013. This test introduced loads into the occupant volume through its CEM attachment points until the ultimate, or crippling, load was reached. By loading the occupant volume through the CEM components, the test load path is similar to the load path that would be traveled by collision loads during activation of the CEM system.

This paper presents the results of the crippling test, discusses the sequence of buckling that was observed to occur in the test, and compares the results of the test with the results from FEA of the test conditions. During the crippling test, the car exhibited a crippling load of 1.1 million pounds. This value is consistent with crippling loads reached by two Budd Pioneer cars that were previously tested in an FRA program. The buckling sequence of the members making up the M-1's occupant volume were particularly well-captured by strain gages during this most recent test. The load path through the occupant volume and the sequence of progressive buckling of structural members is discussed. Additionally, the presence of existing damage and previously-repaired areas and their likely effects on the crippling behavior of the car are discussed.

\section{INTRODUCTION}

Currently, passenger railcars in use on the general railroad system in the United States are required both by regulation [1] and industry standard [2] to possess a longitudinal strength sufficient to resist an 800,000 pound load applied to the line of draft. Under this load, the carbody must not experience permanent deformation. In 2011, the Railroad Safety Advisory Committee's (RSAC) Engineering Task Force (ETF) adopted a set of alternative criteria and procedures for evaluating the OVI of passenger railcars of alternative designs [4]. These alternative criteria and procedures are intended to be applied by an entity seeking a waiver from FRA of certain current regulations. By evaluating the subject railcar against one of the alternative criteria using the agreed-upon procedures, the entity seeking the waiver may demonstrate that the subject vehicle possesses an equivalent level of safety to a vehicle that complies with the conventional requirements. The alternative criteria and procedures for OVI permit a combination of elastic 
testing and extrapolation analysis to be used to demonstrate a passenger car's compliance with the alternative OVI criteria.

Previously, FRA-sponsored research investigated the alternatively-evaluated OVI of two Budd Pioneer passenger railcars [5]. Similarly to the current program, the previous testing was conducted by Transportation Technology Center, Inc. [6]. This crippling test was preceded by an 800,000 pound elastic line of draft load test in which data was collected for model validation. This previous program validated the overall approach of utilizing a combination of testing and FE analysis to evaluate the crippling load of a passenger railcar. Additionally, this previous program demonstrated that the 1.2 million pound crippling load adopted by the ETF as one of its OVI criteria was a reasonable description of the minimum crippling load to be found in an 800-kip compliant railcar of conventional design. The progress of and results from the previous research program have been detailed in several recent publications [7],[8],[9].

A second FRA research program on OVI is currently underway, seeking to expand on the knowledge developed by the Pioneer program. One objective of this program is to develop further guidance on applying the alternative criteria through tests and analyses. The current program used a combination of elastic testing, FE analysis, and destructive testing to evaluate the crippling behavior of the subject railcar. A second objective of this research was to further understand the collision load path through the occupant volume of this car. Because the M1 car used in this program was originally constructed to meet the 800-kip buff load requirement but is being tested against the new, alternative criteria, the results of the crippling load test will help establish the equivalence of OVI between conventionally-designed railcars and those that achieve alternative compliance. Additionally, by performing a destructive crippling test on a second vehicle design, the results of this program may increase confidence in the 1.2 million pound crippling load adopted by the ETF.

\section{TEST ARTICLE}

The current program used a Budd M1 passenger railcar that had been in commuter rail service prior to being retired. The Budd M1 railcar is a conventional North American passenger railcar design utilizing steel construction for the carbody structure. This railcar was originally designed to be compliant with the 800,000 pound line of draft elastic load requirement.

The particular car used in the crippling test program, M1 \#9614, was donated to FRA and retrofitted with crash energy management (CEM) components on both ends during a previous research program. These CEM components included floor- and roof-level energy-absorbing components designed to crush after a prescribed level of force had been reached during a collision. The components were arranged such that during normal service, the longitudinal loads would be introduced into the occupant volume through the conventional line-of-draft. However, collision loads would be introduced through the energy-absorber attachment locations at the ends of the car. This particular car was used in a high-energy train-to-train impact test intended to demonstrate the effectiveness of the CEM features [10].

For the current OVI program, the CEM features were removed from the car in order to provide access to the locations where the energy-absorber components attach to the occupant volume. The intent of the current program was to introduce loads into the occupant volume at the locations where collision loads would enter the occupant volume. The M1 car with and without its CEM features can be seen in Figure 1.

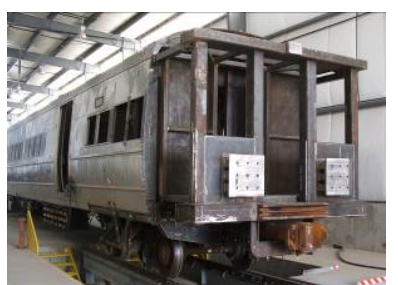

Figure 1. M1 \#9614 with (left) and without (right) CEM Features
Prior to the current testing program, the M1 car was inspected by TTCI. Several areas of damage were identified, likely caused by the high-energy CEM impact test. Several repairs were made to the car prior to the first OVI test. These repairs included the installation of patches on the side sills over areas where cracks were found and the replacement of a patch of damaged sidewall with structure taken from another M1 car. Both of these repairs were made to the same area of the car, under the third window from the F-end. The replacement sidewall was only installed on the right side of the car, as only that side was damaged. Side sill patches were placed on both side sills in order to maintain a symmetric stiffness on both sides of the car. These repairs are shown in Figure 2.
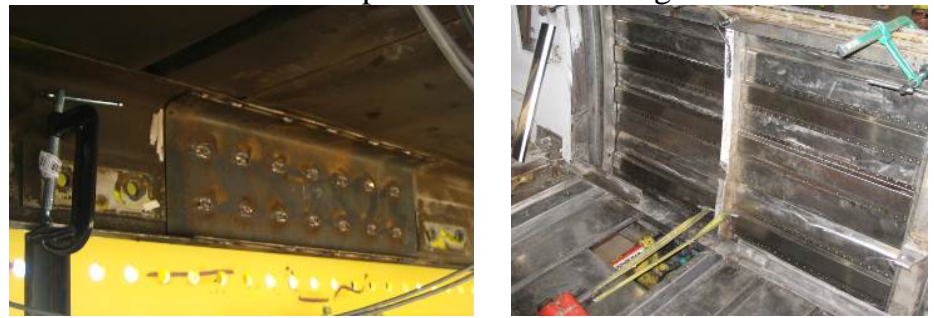

Figure 2. Side Sill Patch (left) and Side Wall Patch (Right)

\section{ELASTIC TEST}

The primary purpose for performing this 800,000 pound test was to generate data for use in model validation, not to demonstrate that the car complied with the buff strength requirement. An 800,000 pound test of M1 \#9614 was performed at TTC on March 13, 2013 where the car was loaded through its floor-level energy absorber supports. This change in load placement, compared with the conventional line of draft loading, was made to simplify the overall testing program while still providing data for comparison with the models.

The same test frame at TTC was used to load and restrain the car during the 800,000 pound test and during the crippling load test. Because the crippling load test placed the loads at the floor- and roof-level energy-absorber supports, placing the 800,000 pound load at the floor-level energy absorber supports would simplify the overall testing program. Since data from an 
800,000 pound load at either the line-of-draft or at the energyabsorber supports could be used for model comparison, it was decided to apply the loads at the floor-level energy-absorber supports. While the test frame had been used in the previous Pioneer testing program, this was the first load test to load a passenger car through only its floor-level supports.

There were several unanticipated results during this test. The carbody appeared to lift off of its trucks during the test. While the carbody was expected to bow upward, the uplift (both visually observed and measured during the test) was larger than expected. Also, the carbody appeared to rotate while in its frame, with one side of the car lifting upwards by more than the other side. Finally, it appeared that several areas of the side sills of the car experienced localized permanent deformation during the 800,000 pound energy-absorber load test.

To account for the unanticipated lift and roll of the carbody, the boundary conditions of the FE model were adjusted following the test. By adjusting the boundary conditions of the FE model after the test, the overall response of the car could be captured by the post-test FE model.

The load versus displacement behavior measured on the left, center, and right of the car during the test are plotted against the corresponding calculations from the post-test FE model in Figure 3. As can be seen in these figures, the forcedisplacement behavior calculated in the post-test FE model on the left side of the car and at its centerline falls within a +/$10 \%$ envelope of the results measured during the test at the corresponding locations. The results on the right side of the car do not fall within this $+/-10 \%$ envelope.

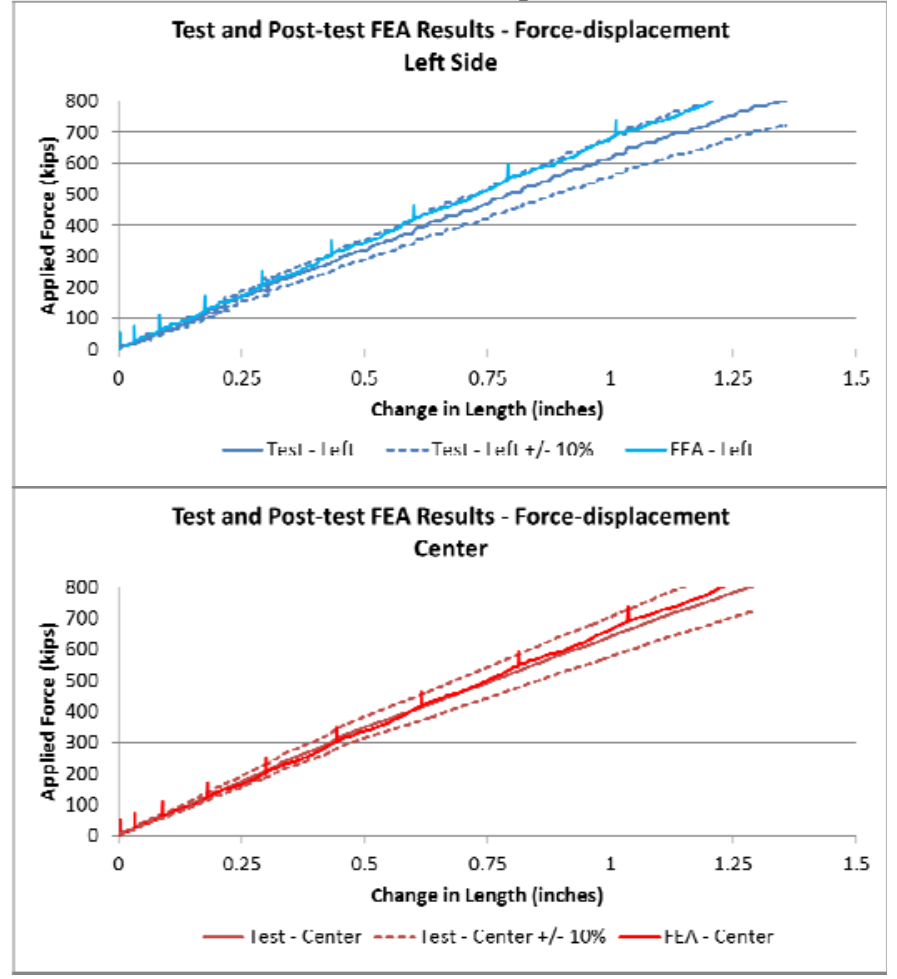

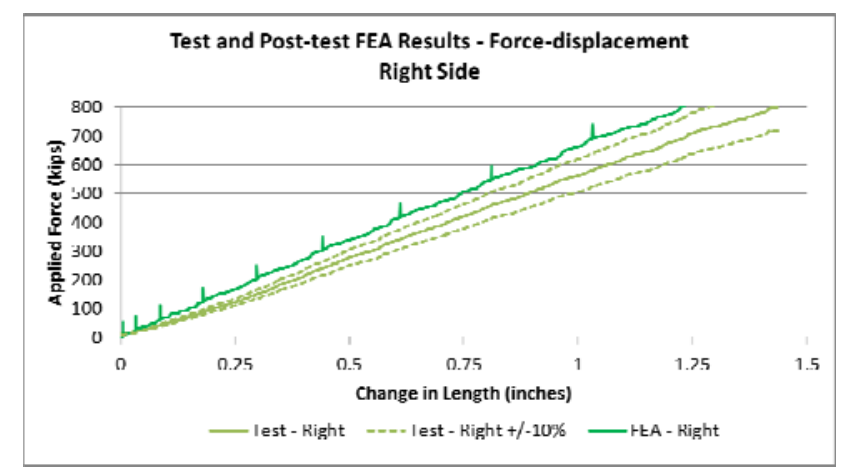

Figure 3. Force-displacement Behavior for Left, Center, and Right Sides of Car under 800-kip load

\section{CRIPPLING TEST SETUP}

The crippling test of M1 \#9614 was performed at TTC on July 17, 2013. While the 800,000 pound test loaded and reacted the car through its floor-level energy-absorber supports, the crippling test used both the floor-level and roof-level energy absorber supports at each end of the car. The F-end of the car was the live end (i.e. loads introduced into the car) and the B-end was used as the restraint end (i.e. loads reacted out of the car, into the frame). The car is shown within the frame, prior to the test, in Figure 4.

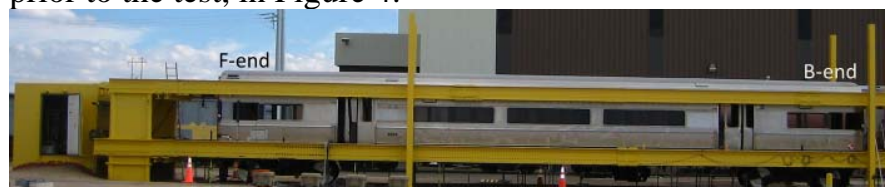

Figure 4. M1 \#9614 in Test Frame, Pre-test

Load was introduced into the car through four hydraulic actuators on the F-end. These actuators were individually manipulated until the car was positioned snugly within the frame and there was no slack between the actuators and the loading locations on the car. Once the slack was taken out of the system, displacement control was employed on the hydraulic system to maintain an equal stroke length in each of the four actuators. Because the displacement of the actuators was controlled, the load applied by each actuator was able to vary, based on the amount of force necessary to achieve the prescribed displacement at each location.

\section{CRIPPLING TEST INSTRUMENTATION}

A total of 169 channels of instrumentation were used during this test, as shown in Table 1 . The instrumentation included string potentiometers between the car and the ground, high-elongation strain gages throughout the occupant volume of the car, and load cells between the car and the test frame at both the F-end and the B-end.

Table 1. Crippling Test Instrumentation Summary

\begin{tabular}{|c|c|}
\hline Type of Instrumentation & Number of Channels \\
\hline High-extension Strain Gages & 81 \\
\hline String Potentiometers & 71 \\
\hline Load Cells & 8 \\
\hline Pressure Transducers & 4 \\
\hline LVDTs & 4 \\
\hline Temperature & 1 \\
\hline Total & 169 \\
\hline
\end{tabular}


The instrumentation was installed on the car at 9 approximately planar cross-sections along the length of the car, as shown in Figure 5. Cross-sections 1 and 9 correspond to the ends of the car; as such, no strain measurements were made at these cross-sections. While the original intent was to install all strain gages and string potentiometers in the same plane at a given location along the length of the car, this was not always possible due to carbody features, such as a bracket on the underframe. Strain or displacement output was requested in the FE model at locations corresponding with the actual instrumentation placement in the tested car.

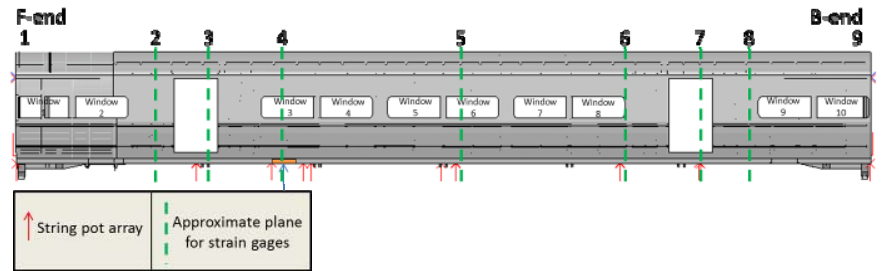

Figure 5. Cross-sections for Instrumentation

High-extension strain gages were installed throughout the car on the longitudinal load-carrying members and on the roof. The members included the center sill, side sills, belt rails, upper window rail, and roof rail. At each instrumented cross-section, two gages were placed on each side sill and each side of the center sill. At each cross-section, one gage was used on each side's belt rail, upper window rail, roof rail, and roof. A schematic representation of the strain gage placement on the cross-section of the M1 is shown in Figure 6.

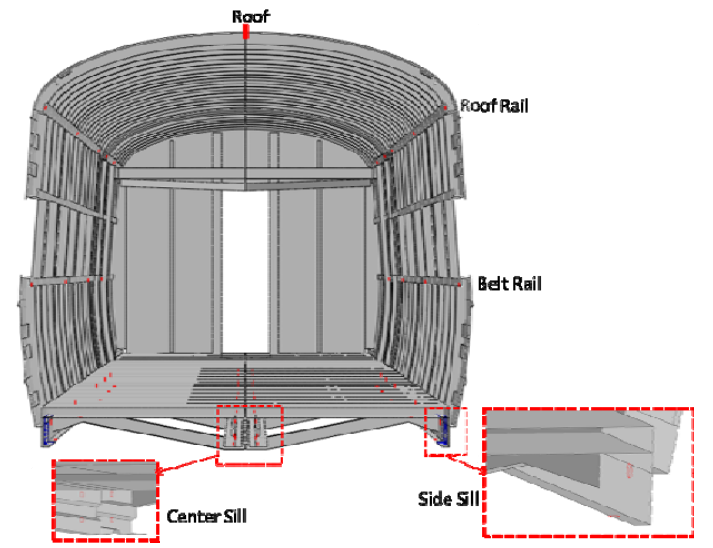

Figure 6. Strain Gages on Structural Members

High-extension strain gages were used in this test for several reasons. Because the test was designed to load the car up to its ultimate or crippling load, strain gages capable of measuring the member strains beyond yield were desirable. Because the materials used to construct the M1 car were highstrength, the high-elongation gages were needed to effectively capture strains beyond yield.

String potentiometers were used during the crippling test to measure displacements at the ends of the car and on the underframe of the car along its length. At the car ends, the string potentiometers were oriented parallel to the rails, in the longitudinal direction. Longitudinal string potentiometers were installed adjacent to the four energy-absorber support plates on L-brackets.
At each of the instrumented cross-sections of the underframe, string potentiometers were installed on both side sills and the center sill of the car. At each location, a vertical, lateral, and longitudinal (VLL) array of string pots was installed between the ground and a bracket attached to the car. These arrays have been successfully used in previous quasistatic tests of passenger equipment to resolve the 3-dimensional motion of a point into its X, Y, and Z components [5]. Because the measurements made at locations with VLL arrays are less susceptible to errors due to off-axis motions, the longitudinal displacements from VLL arrays at each end of the car are used to describe the overall change in length of the car's underframe.

\section{FINITE ELEMENT ANALYSIS}

Prior to the crippling test, FE analyses of the M1 car were performed. Volpe's FE model was pre-processed using Abaqus/CAE [3]. The simulation was executed using a dynamic explicit solver, Abaqus/Explicit. While the physical test was planned to be a quasi-static test, an explicit solver was selected to allow the model to experience large deformations and buckling.

The FE model of the car represented the full length and full width of the car. The model featured a total of $\sim 750,000$ nodes. The structure of the carbody was meshed primarily using shell elements. Beam elements were used to represent some beam members in the occupant volume of the carbody. Additionally, rigid shell elements were used to represent the load and reaction plates at the energy-absorber supports. Rigid beam elements were used to represent the brackets to which the string pots on the ends of the car and on the underframe of the car were attached.

Table 2. Element Types Used in FE Model

\begin{tabular}{|c|c|c|}
\hline Element Type & $\begin{array}{c}\text { Element } \\
\text { Description }\end{array}$ & $\begin{array}{c}\text { Number of } \\
\text { Elements }\end{array}$ \\
\hline B31 & Deformable beam & 3,254 \\
\hline MASS & Rigid shell & 8 \\
\hline R3D4 & $\begin{array}{c}\text { Rigid body reference } \\
\text { point }\end{array}$ & 420 \\
\hline RNODE3D & Triangular shell & 1,944 \\
\hline S3R & $\begin{array}{c}\text { Quadrilateral shell, } \\
\text { full integration }\end{array}$ & 757,384 \\
\hline S4R & $\begin{array}{c}\text { Quadrilateral shell, } \\
\text { reduced integration }\end{array}$ & 286 \\
\hline & Total \\
\hline
\end{tabular}

Prior to the test, material coupons were taken from several components on a similar M1 car, and subjected to tensile testing to generate stress-strain behavior for input to the FE model. These material coupons were taken from the center sill, side sill, wall panel, roof member, floor panel, cross-bearer, and sidewall post. A minimum of three tensile samples were taken from each area. The average behavior was used to generate bilinear elastic-plastic material characteristics, which were used to define the materials throughout the FE model. In the Abaqus solver, metal plasticity is defined as a function of true stress and plastic strain. The plastic behavior of each material, as input to the FE model, is plotted in Figure 7. 


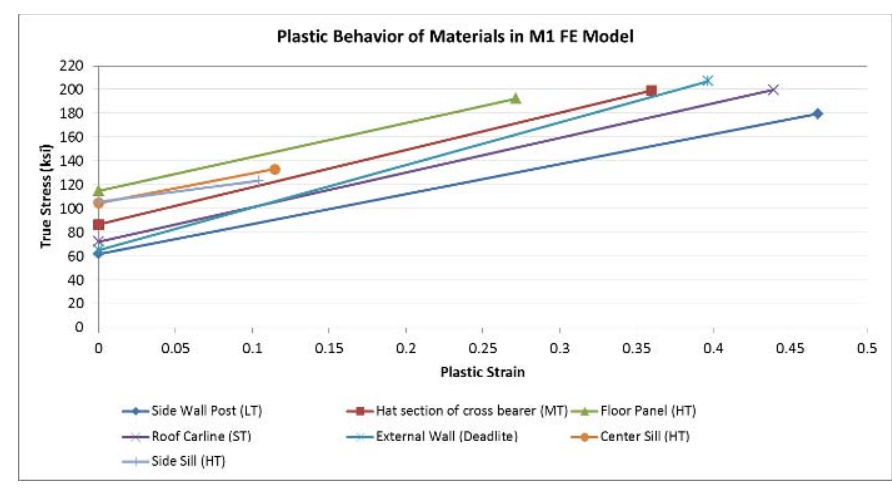

Figure 7. Plastic Behavior of Materials Used in M1 FE Model

Load was introduced into the model through the floor-level and roof-level energy absorber supports on the F-end of the car. Four rigid plates were modeled adjacent to the locations where the hydraulic rams would load the car during the test. These plates were then given a prescribed displacement-time behavior. Load was transferred into the FE model through contact between each plate and the structure of the car. At the $\mathrm{B}$-end of the car, a similar set of rigid plates were placed adjacent to the B-end energy-absorber plates. The B-end plates were not permitted any displacement during the test. No further constraint was placed on the carbody. The ends of car 9614 and the FE model are shown in Figure 8. Note that in the image of the FE model the load plates are shown, obscuring the visibility of the energy-absorber supports.

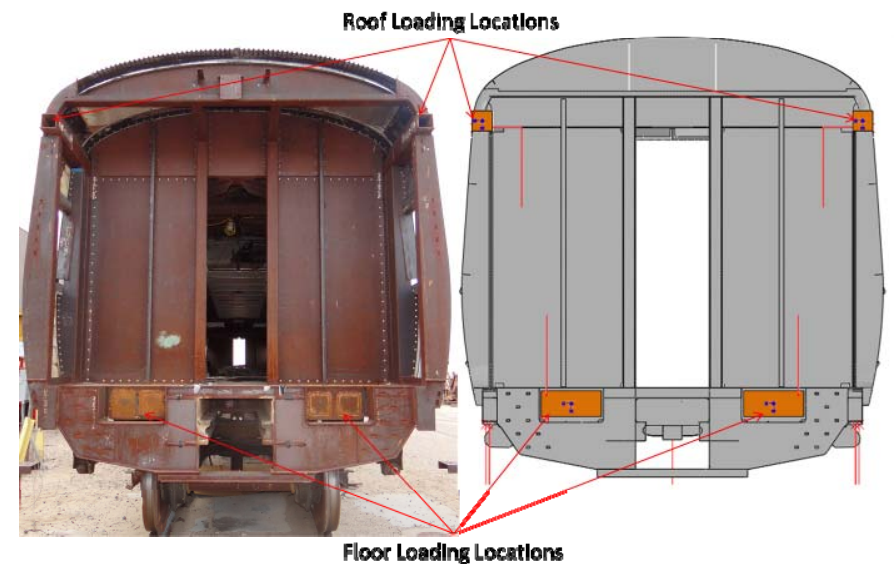

Figure 8. Loading Locations on Car 9614 (left) and FE Model (right)

Because the test was simulated as a slow dynamic event, checks were made of the simulation results to ensure that undesirable dynamic effects were not being inadvertently introduced into the results. The ETF has adopted a set of criteria and procedures for evaluating passenger railcars using analysis techniques including FEA [4]. These criteria and procedures include a methodology for determining whether a slow dynamic analysis is sufficiently free from dynamic effects as to be considered quasi-static. The total force on the F-end (live end) and the B-end (reaction end) of the car are plotted against time in Figure 9. A +/-5\% envelope on the F-end force is also plotted in this figure. The B-end force should be within this envelope for an analysis to be considered quasi-static. This figure indicates that the model meets this condition.

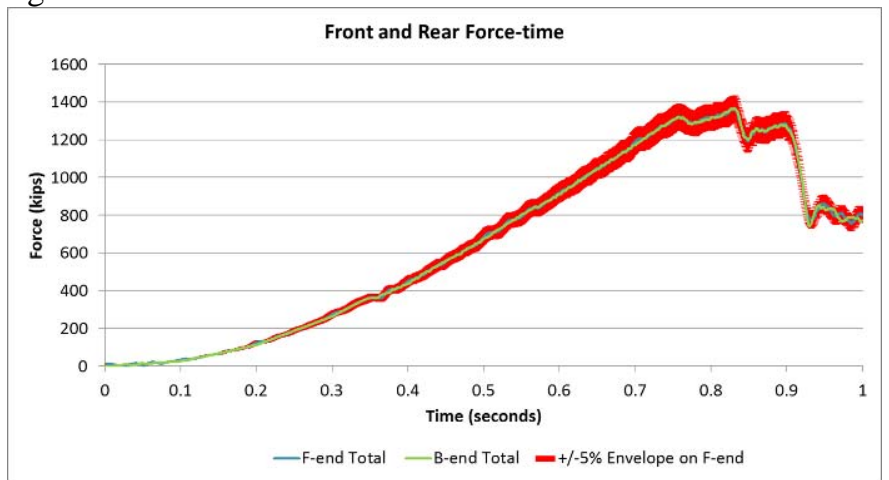

Figure 9. F-end and B-end Forces from FE Model

\section{CRIPPLING TEST AND ANALYSIS RESULTS}

The crippling test successfully loaded the M1 car up to its ultimate load, resulting in crippling of the vehicle's structure. The car was loaded in intermediate steps of 200, 400, and 600 kips with a return to near-zero load between steps. Following the 600-kip load step, the load was increased to 800 kips and held at this value. The load was not actively reduced after reaching 800 kips. Any decrease in load beyond this point was a result of buckling or other plastic deformation of the carbody structure. The total F-end and B-end loads are plotted against time in Figure 10. This figure indicates that the total load reacted by the B-end of the car is approximately equal to the load being introduced on the F-end throughout the test.

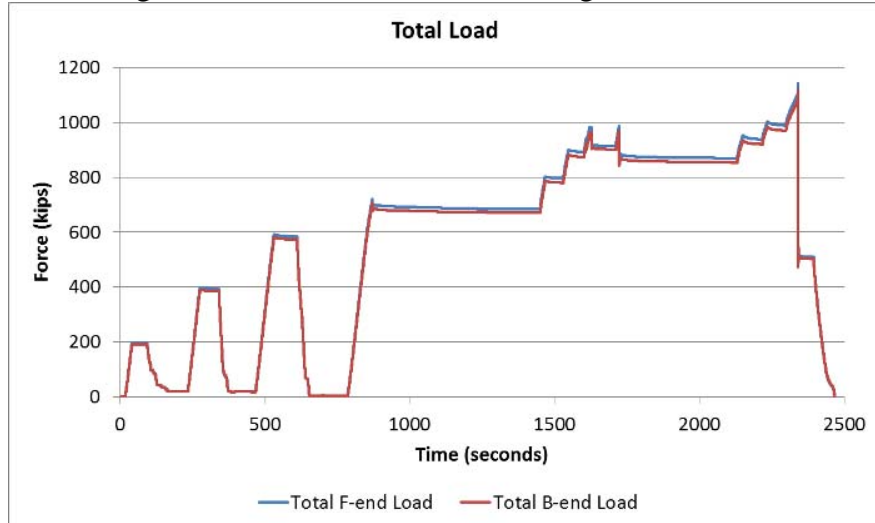

Figure 10. Total F-end and B-end Loads, Crippling Test

Prior to reaching the crippling load, the occupant volume experienced permanent deformation or buckling in several locations. The roof and roof rails buckled on both the F-end and B-end of the car. The center sill buckled toward the F-end of the car, while the side sills buckled at several locations along the length of the car on both the left and right sides. A post-test view of the buckled car within the test frame is shown in Figure 11. 


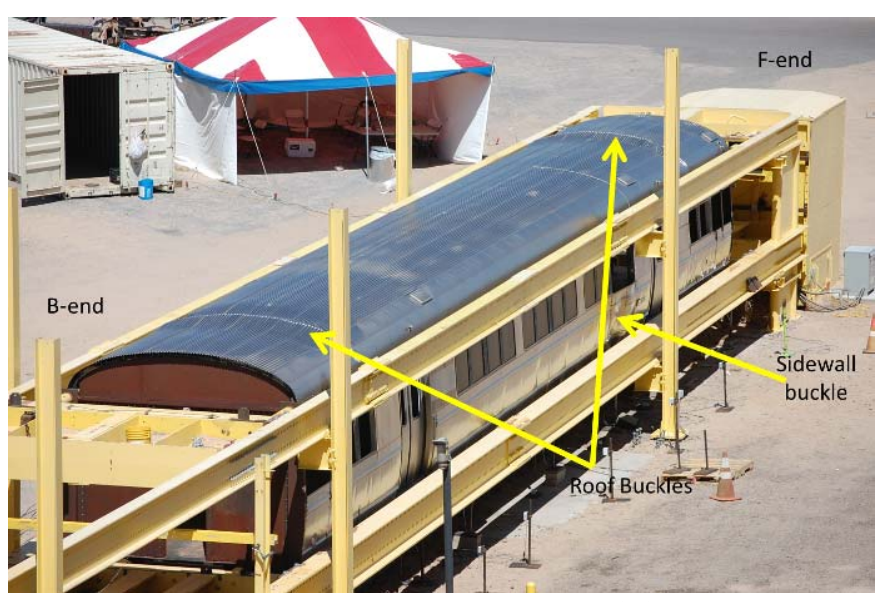

Figure 11. Post-test Overhead View of Crippled Car

One of the key measurements made during the crippling test was the applied force versus change in car length, typically referred to as a force-displacement characteristic. For the crippling test of Budd M1 9614, the total applied force is the sum of the forces applied by the two floor-level and two rooflevel actuators on the F-end of the car. This total force is plotted against the change in the length of the car. This car featured a VLL array of string potentiometers installed at the left, center, and right sides of the car on both the F-end and Bend. The total force is plotted against the change in length as measured on the left, center, and right sides of the car in Figure 12. While the left side and center string potentiometers indicate nearly the same change-in-length for a given applied load, the right side string potentiometers indicate a slightly stiffer response on this side of the car.

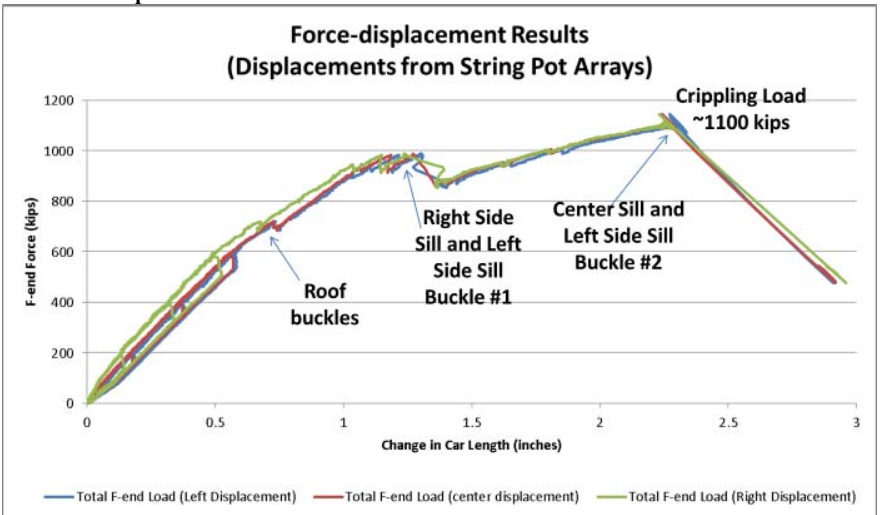

Figure 12. Force-displacement Characteristic from Test

Figure 12 includes annotations indicating the regions on the force-displacement characteristic where several buckling events occurred during the test. The timing of these events was ascertained through post-test review of the strain gage data. Post-test inspection of the car revealed several buckles to have occurred at or adjacent to strain gages. A detailed discussion of the sequence of buckling events is discussed later in this paper.

The crippling load of the M1 car in the test was approximately 1.1 million pounds. During the previous testing program, two Budd Pioneer passenger railcars were loaded to crippling using a similar test setup as the M1 test [5]. In that program, the cars buckled at 1.15 and 1.2 million pounds, respectively. The M1's measured crippling load is therefore consistent with the crippling load measured for two other retired passenger cars that had been retrofitted with CEM systems. All three cars (i.e. the two Pioneer cars and the M1 car) were originally designed to meet the 800,000 pound lineof-draft requirement.

The M1 car was instrumented with load cells at the four Fend load introduction locations and at the four B-end load reaction locations. This instrumentation arrangement allowed the load path to be studied by comparing the load being introduced at each location with the load being reacted at each location. Figure 13 contains a plot of the total F-end floor load and the total B-end floor load plotted against the change in car length during the test. Note that the change in car length used to generate this plot was obtained by using the displacement transducers at the center of each end of the car.

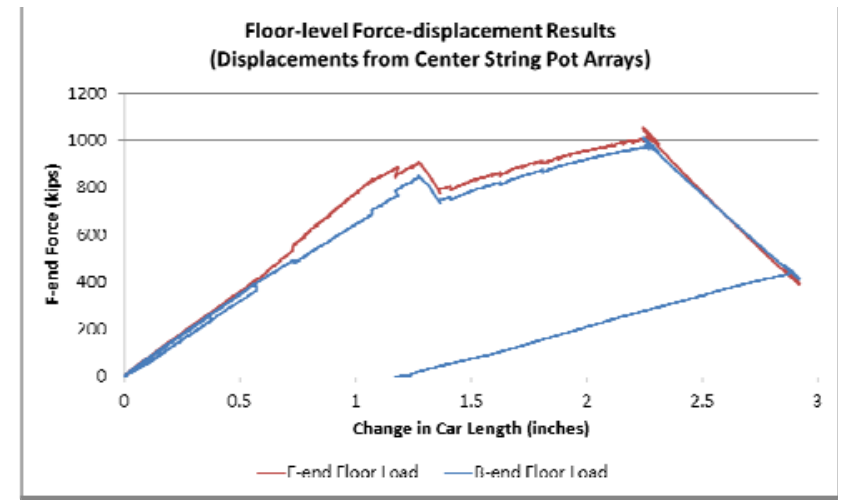

Figure 13. F-end and B-end Floor-level Loads

Over approximately the first one-half inch of carbody compression the F-end and B-end floor loads are approximately equal. Following this point, the F-end loads are consistently higher than the B-end loads. As seen in Figure 10, the total Fend load is equal to the total B-end load throughout the test. Therefore, the additional load being borne by the F-end must be reacted by the roof-level restraint locations at the B-end of the car.

This behavior is confirmed by plotting the total F-end roof loads and total B-end roof loads. This plot is shown in Figure 14. Up to one-half inch of carbody compression, the applied roof loads and the reacted roof loads are approximately equal. The F-end load then begins to reduce as the carbody experiences further compression. The B-end load continues to rise, however. As discussed further in this paper, the F-end roof buckled prior to the B-end roof, causing a shift in the load path from one end of the car to the other during the test. 


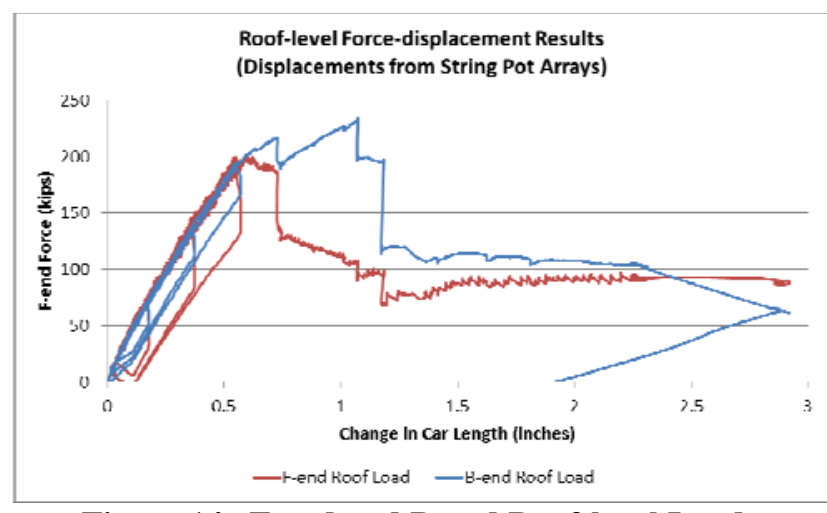

Figure 14. F-end and B-end Roof-level Loads

Prior to performing the crippling test, the FE model was used to simulate loading of the car up to its crippling load. The force-displacement behaviors calculated by the FE model are compared with the test measurements corresponding to each loading location in the following figures. For this set of results, the applied load at an individual location (e.g. the left-side floor-level location) is plotted against the change in length measured for the underframe on that side of the car.

The floor-level force-displacement results are compared between the FEA and test results in Figure 15 for the left-side floor-level load location. On the left side of the underframe, the test and FE results are in good agreement up to a just less than 500 kips. This drop in load occurs at a change in length of approximately 1.25 inches. The FE model continues to carry an increasing amount of load, up to a load of 600 kips, while the test results exhibit a sudden drop in load after reaching 500 kips. The drop in force measured during the test corresponds to the buckling of the right and left side sills that are indicated in Figure 12. Following this drop in load during the test, the left side of the floor continued to carry an increased load as the car was further compressed. The tested car and the FE model both exhibit the same characteristic behavior, where the load increases following a short drop in load. During the test, the left side floor load increased to a maximum of slightly more than 600 kips. In the pre-test FE model, the left side floor load increased to a maximum of slightly less than 600 kips.

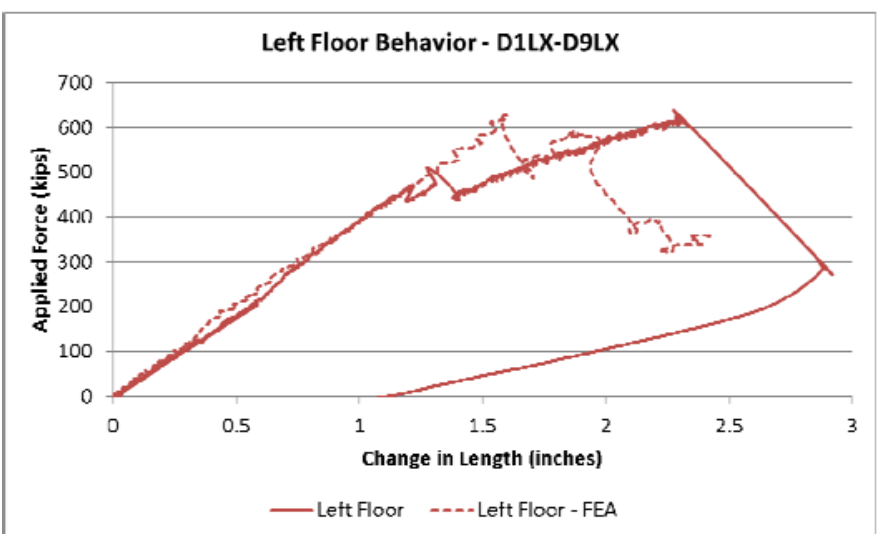

Figure 15. Force-displacement Behavior, Floor Level, Test and FEA (Left Side)
The test and FE results for the right-side floor-level loading location are compared in Figure 16. Similarly to the left-side behavior, both the test and the FEA results are in good agreement during the initial loading. On the right side, the results are in good agreement up to approximately 1.1 inches, or a load of approximately 400 kips. At this point, the test results exhibit a drop in load with increasing car shortening, while the FEA results continue along the previous slope. Following this drop, the test results begin to climb with increasing car shortening. However, the slope of the curve following the buckling event is greatly decreased. The maximum load introduced into the car through the right-side floor loading location does not exceed the load where the buckle occurred. The FE results reach a maximum load of slightly more than 600 kips before buckling occurred in the model.

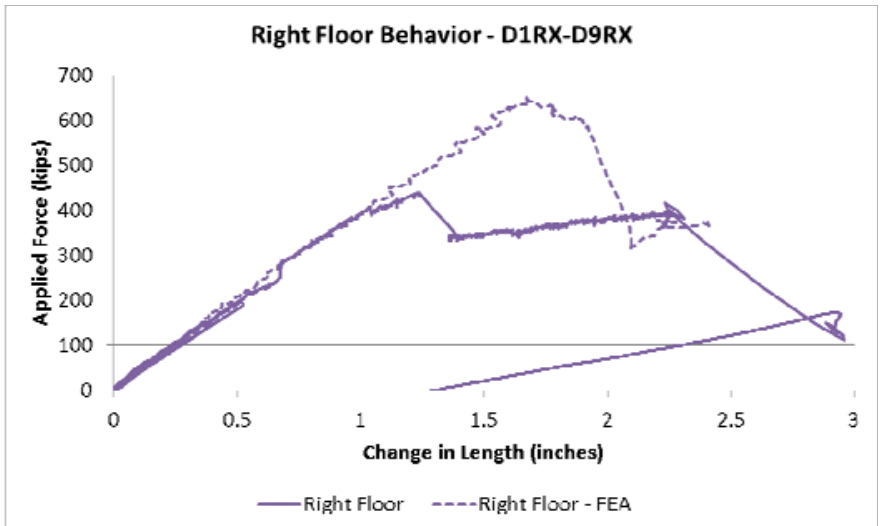

Figure 16. Force-displacement Behavior, Floor Level, Test and FEA (Right Side)

The test and FEA results for the left side roof loading location are compared in Figure 17. For both the left and right side roof characteristics, the change in car length was calculated by using the displacement measurements made at the roof-loading locations on both ends of the car. The roof test data exhibit a strong hysteresis between loading and unloading behavior during each of the load cycles. In general, the loading curve has a similar slope to the loading curve calculated by the FE model. The roof in the test car buckled at a load of approximately 100 kips, while the roof in the FE model buckled at a load of approximately 140 kips.

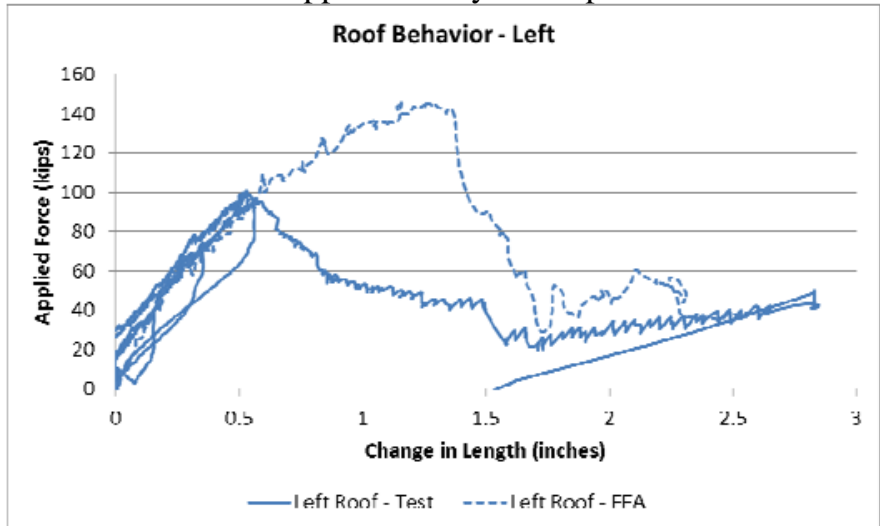

Figure 17. Force-displacement Behavior, Roof Level, Test and FEA (Left Side) 
The test and FEA results for the right side roof loading location are compared in Figure 18. The right side test measurements exhibit a much cleaner force-displacement relationship than the left-side roof measurements. The loading behavior follows the same curve during each load cycle of the test. The right side test measurement reaches a peak force of 120 kips before buckling occurs. In the FE model, the rightside behavior is similar to that of the left side. The right side of the FE model reached a peak load of approximately 140 kips before buckling.

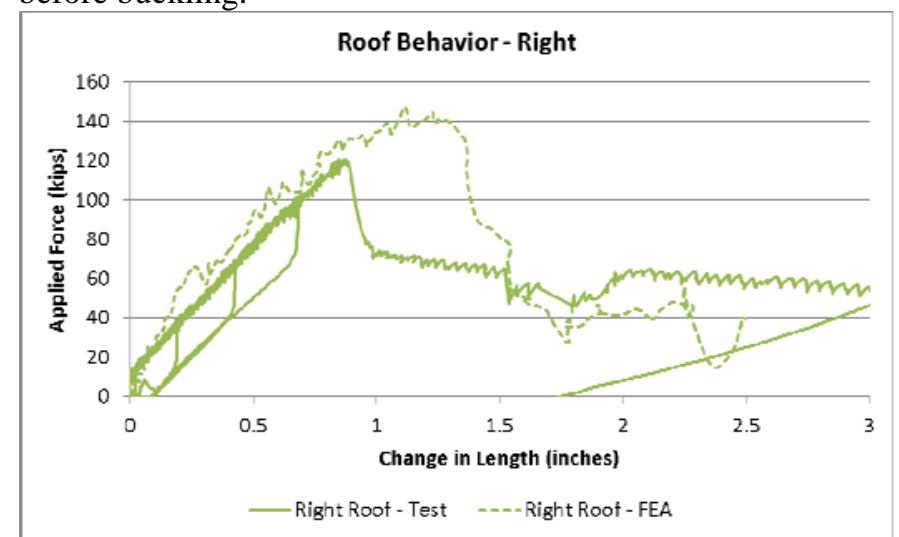

Figure 18. Force-displacement Behavior, Roof Level, Test and FEA (Right Side)

The roof of the pre-test FE model was modeled conservatively, as the physical car featured a corrugated roof that was approximated as a planar roof in the model. As can be seen in the preceding two figures, the roof of the tested car buckled at a lower load than the model on both the left and right sides of the car. It is likely that pre-existing damage to the sidewall and roof in the vicinity of each area of buckled roof may have contributed to the buckling behavior exhibited by the roof on both ends of the car. The overall buckling sequence and correlation with areas of pre-existing damage are discussed in the following section.

\section{DISCUSSION OF BUCKLING SEQUENCE}

During the pre-test inspection of the M1 car, several areas of the underframe and the interior of the car were noted as having pre-existing damage. Several areas of the side sill had been previously straightened in an attempt to remove buckles. However, small dents remained. Several areas of buckling from the 800,000 pound test were unchanged prior to the crippling test. The locations of pre-existing buckles were indicated directly on the car prior to the test, as it was anticipated that such areas could serve as initiation sites for further damage during the test.

The car was inspected again following completion of the crippling test. Several areas of the car had visible damage, in the form of buckles. Buckles were observed on the center sill, both side sills, and the wall and roof structures on both the Fend and B-end of the car. As anticipated, several areas of preexisting damage had in fact grown larger during the test. The post-test inspection revealed that several areas of the car had buckled at or near strain gages. By reviewing the strain-versustime data recorded by each channel near a location with damage, it was possible to re-construct the sequence of buckling events that occurred during the test.

Figure 19 is a plot of the total applied force versus time over the entire load sequence during the physical test. A series of vertical lines have been added at the times corresponding to strain gage readings that indicated one or more members was experiencing buckling. Based upon the strain gage measurements, five buckling events have been identified during the loading sequence. These events have been correlated with damage noted from the post-test visual inspection of the car. From this figure, it is apparent that for events 2-4 the buckling event corresponded to a measurable drop in the total applied load.

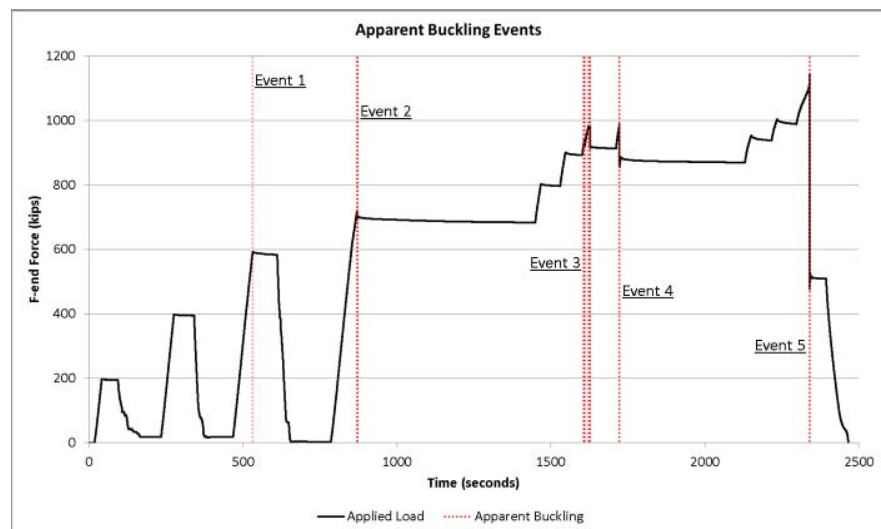

Figure 19. Force-time History for Test with Buckling Events Indicated

The five buckling events depicted in the previous figure occurred in several members throughout the carbody.

Table 3 contains a summary of the five buckling events and locations of the strain gages that indicated buckling behavior during each event.

Table 3. Apparent Buckling Sequence

\begin{tabular}{|c|c|c|}
\hline Event & Location & Time (s) \\
\hline 1 & Cross-section 2, left roof rail & 530 \\
\hline \multirow{2}{*}{2} & Cross-section 2, right roof rail & \multirow{2}{*}{870} \\
\cline { 2 - 2 } & Cross-section 2, roof & \\
\hline \multirow{3}{*}{3} & Cross-section 8, roof & \multirow{2}{*}{1610} \\
\cline { 2 - 2 } & Cross-section 8, right roof rail & \\
\cline { 2 - 2 } & Cross-section 8, left roof rail & 1620 \\
\cline { 2 - 2 } & Cross-section 6, left side sill, web & 1630 \\
\hline \multirow{2}{*}{4} & Cross-section 4, right side sill, flange & \multirow{2}{*}{1720} \\
\cline { 2 - 2 } & Cross-section 6, left side sill, flange & \multirow{2}{*}{2340} \\
\hline \multirow{2}{*}{5} & Cross-section 4, left side sill, web \\
\cline { 2 - 2 } & Cross-section 4, left side sill, flange \\
\cline { 2 - 2 } & Cross-section 4, center sill (all gages) & \multicolumn{1}{|c|}{} \\
\hline
\end{tabular}

The first apparent buckling event was indicated by the strain gage on the left roof rail at cross-section 2. This is the location closest to the left roof loading location on the F-end of the car. This buckling event occurs at nearly the time when the test was paused at $600 \mathrm{kips}$, as seen in Figure 19. Because the car was subsequently unloaded, there was no immediate drop in load associated with this buckling. However, when loading resumed, the load path into the car was altered, as this location had begun to buckle. Figure 20 shows a post-test image of this 
damage. This figure also shows damage to the upper window rail at the same cross-section of the car. The upper window rail was noted as having pre-existing damage, which may have contributed to the buckling behavior at this particular location.

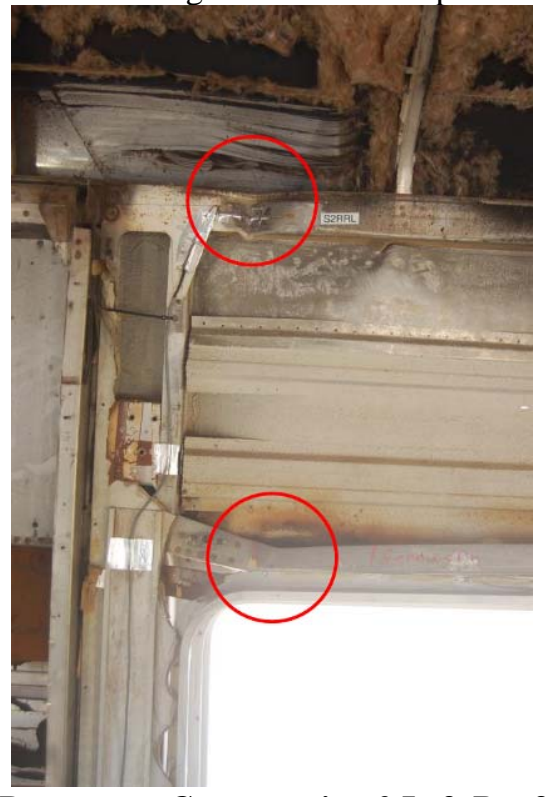

Figure 20. Damage to Cross-section 2 Left Roof and Upper Window Rails

The second buckling event occurs at approximately 870 seconds. At this stage of the test, the applied load has reached approximately 700 kips. The right roof rail and the roof structure itself buckled at this load. Because the roof buckling was clearly visible to the test observers, the test was temporarily paused while the car was examined. The load was then increased to the planned dwell load at 800 kips. The damage to the right side of the roof closely resembles the damage observed on the left side of the roof that is shown in Figure 20. Similarly to the left side, the right side upper window rail had pre-existing damage prior to the crippling test.

The third buckling event occurred at approximately 1610 seconds. During a 20-second period, both the B-end roof and a segment of the left side sill began buckling. The damage to the B-end roof resembled the damage to the F-end roof, with buckling evident on the roof itself, the roof rails, and the upper window rails. Similarly to the F-end, the B-end upper window rails were noted as having pre-test damage in the areas that would eventually buckle during the test. The total applied load was approximately 975 kips when these areas buckled. The total load dropped by approximately 60 kips during this buckling event.

Following the third buckling event, the load began to rise as the F-end displacement was increased. The total applied load had increased to approximately 975 kips for the second time when the fourth buckling event occurred. At this time, the flange of the right side sill and flange of the left side sill buckled. The left side sill's flange buckled adjacent to an area of its web that had buckled during event 3 . Figure 21 shows a pre- and post-test view of this area with the existing damage noted in the left-hand image. From the post-test photo, it is apparent that this pre-existing damage has spread during the test, i.e. the existing damage served as an initiation site for further buckling during the test.

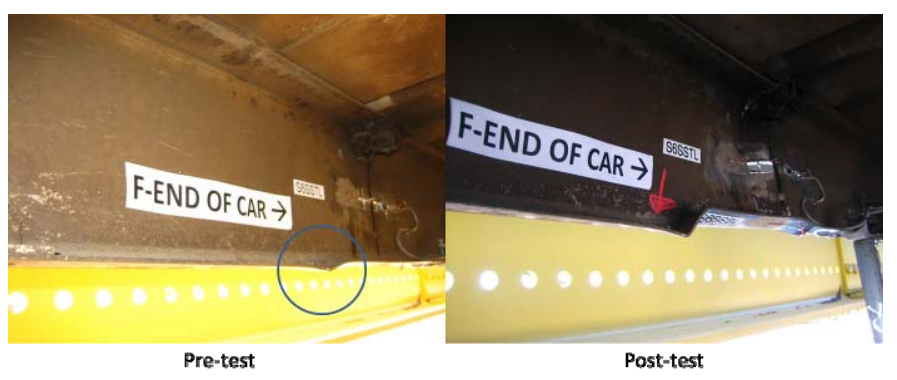

Figure 21. Cross-section 6 Left Side Sill Pre-test (Left) and Post-test (Right) Damage

Following buckling event 4 , the test was paused while the car was photographed and the instrumentation readings were examined. The load was then increased until the carbody completely crippled at a time of approximately 2340 seconds. At this time, the left side sill and the center sill experienced a near-simultaneous failure. The area of the left side sill that failed was adjacent to the region of the center sill that buckled. Both of these regions were remote from the region of left side sill that had previously buckled. This indicates that even though the left side sill had already buckled toward the B-end of the car, the side sill at the F-end of the car was still part of the load path from the F-end to the B-end. Figure 22 shows the buckled left side sill and the buckled center sill following the test.
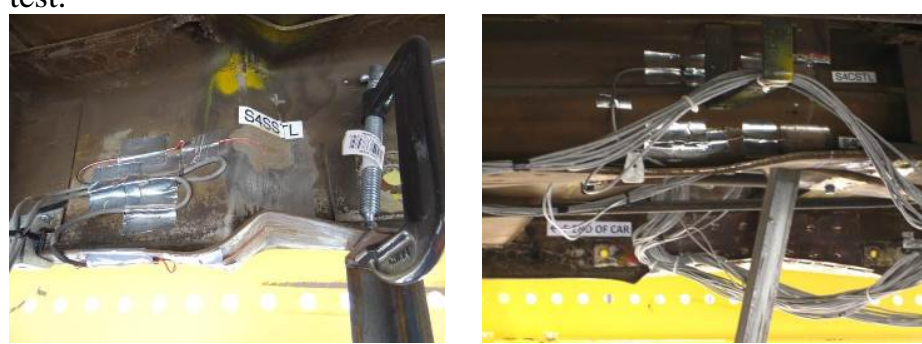

Figure 22. Buckling to Left Side Sill (Left) and Center Sill (Right) During Event 5

Figure 23 shows a schematic profile view of the M1 car with the areas of center sill, left side sill, and right side sill buckling indicated. All three underframe members experienced buckling in the same vicinity, in the area beneath window 3 . The right side sill's damage was entirely contained to this area, whereas the left side sill also experienced buckling further toward the B-end. Based upon review of the strain gage data, it is apparent that the crippling strength of the M1 car was reached when the center sill and side sill failed.

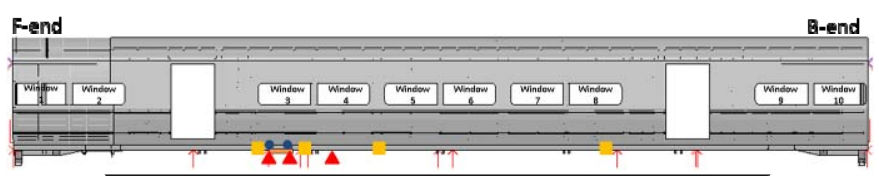

$\Delta$ Center SIII Buckling $\bullet$ Right SIde SIII Buckling Left SIde SIII Buckllng

Figure 23. Areas of Underframe Buckling 


\section{COMPARISON TO PREVIOUS RESULTS}

Prior to this research program, FRA had conducted elastic validation and destructive crippling tests on two passenger railcars of a different design. These Budd Pioneer passenger cars had also been modified to include CEM components. While the Pioneer and M1 cars were both built by the Budd Company to the conventional 800,000 pound buff strength requirement, the structures of the vehicles were somewhat different from one another.

Figure 24 is a plot of the F-end load against the F-end displacement for Budd Pioneer Cars 248 and 244 and Budd M1 9614 as measured in the three crippling tests. Note that the horizontal axis of this plot is the live-end displacement, not the change in car length. The test of Budd Pioneer 248 did not include displacement measurements on the B-end of the car, therefore the change in car length cannot be calculated for this car. However, since all three cars are approximately the same length and were tested using the same frame at TTC it is reasonable to compare the F-end forces and F-end displacements for all three. Further details on the Pioneer tests and corresponding analyses can be found in References 5-9.

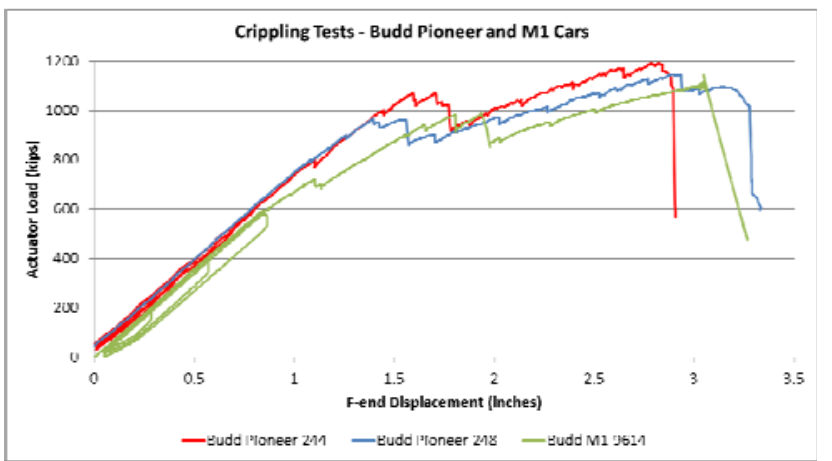

Figure 24. Crippling Test Results for Budd Pioneer and M1 Passenger Cars

The overall sequence of crippling is similar for all three cars. For all three cars, some buckling is apparent at approximately 1-million pounds of applied load. In the Pioneer cars, this buckling is limited to the roof and sidewalls. Following this initial buckling in all three vehicles, the load resumes its rise with increasing displacement as the underframe continues to carry load. Pioneer 244 has the highest crippling load at 1.2 million pounds. Pioneer 248 and M1 9614, each of which had experienced damage prior to its crippling test, each had crippling loads between 1.1 and 1.2 million pounds.

\section{SUMMARY}

An 800,000 pound floor-load test was conducted on a Budd M1 passenger railcar on March 13, 2013. The car chosen for this test had been previously modified with CEM components during a previous FRA-sponsored research program, allowing loads to be introduced into the occupant volume through a collision load path other than along the line of draft. While there were some complications experienced during this test, the results of this test were used to help validate finite element models of the car.

A destructive crippling test of Budd M1 9614 was successfully performed at TTC on July 17, 2013. The load on the car was progressively increased in increments until the ultimate, or crippling load was reached. This ultimate load of 1.1 million pounds was consistent with the results of previous tests of FRA-compliant passenger cars when loaded through an alternative load path.

The results of this test included strain measurements at or adjacent to several regions where buckling occurred throughout the car body. These measurements were useful in reconstructing the sequence of buckling events that occurred during the test. By studying the way that different areas of the carbody buckled during the test, the load path through the occupant volume during an alternative loading is better understood.

One of the observations made during this test was the propensity for areas that had previously been damaged to act as initiation sites for further damage during subsequent loadings. It is likely that these areas of pre-existing damage compromised the structural integrity of the car, resulting in a crippling load that was lower than the crippling load that would have been reached by an M1 car in pristine condition. In a production CEM railcar, care must be taken following a derailment, collision, or other severe loading scenario to ensure that damage is limited to the replaceable CEM components. Postrepair non-destructive testing may be appropriate to ensure that the structural integrity of the repaired occupant volume is equal to the originally-designed level of OVI.

During the crippling test, the loads were introduced into the occupant volume through locations where collision loads from the CEM system would be introduced. The Budd M1 car was originally designed to meet the 800,000 pound buff strength requirement. Because this load is placed along the line-of-draft, the underframe of the car was designed to bear the majority of this load. Based upon the data collected during this test, it is apparent that the Budd M1 car's crippling load was determined by the strength of the underframe (i.e. the center and side sills). This test demonstrated that the OVI of a conventionally-designed passenger car, when loaded according to the alternative procedures, is in agreement with the minimum level of OVI required by the alternative criteria. Therefore, confidence is increased that proper application of the alternative criteria will result in an OVI that is equivalent to that of a conventionally-designed railcar.

\section{ACKNOWLEDGEMENTS}

The tests described in this paper were performed at Transportation Technology Center in Pueblo, CO. Staff from Transportation Technology Center, Inc., helped to develop the test requirements, instrumented the car, collected the data, photographed the car, and documented the results of the test. Arup, under contract with TTCI, also helped plan the test, develop the instrumentation, and conduct FEA independent of Volpe's analyses.

The research discussed in this paper was performed as part of the Equipment Safety Research Program sponsored by the Office of Research and Development of the FRA. Kevin Kesler, Chief, Equipment and Operating Practices Division, reviewed and supported this effort. Luis Maal, Resident 
Engineer Program Manager at TTC, coordinates effort between FRA, Volpe, TTCI and Arup.

The authors would like to acknowledge colleague Patricia Llana of the Volpe National Transportation Systems Center for her ongoing technical advice and support in the research discussed in this paper, particularly associated with the FE model.

\section{REFERENCES}

[1]. Static End Strength, 49 CFR 238.203.

[2]. American Passenger Transportation Association, "APTA SS-C\&S-034-99, Rev. 2. Standard for the Design and Construction of Passenger Railroad Rolling Stock,” June 15, 2006.

[3]. Abaqus version 6.12. Dassault Systems Simulia Corp, Providence, RI, 2012.

[4]. Carolan, M., Jacobsen, K., Llana, P., Severson, K., Perlman, B., and Tyrell, D. (eds). "Technical Criteria and Procedures for Evaluating the Crashworthiness and Occupant Protection Performance of Alternatively Designed Passenger Rail Equipment for Use in Tier I Service." U.S. Department of Transportation, DOT/FRA/ORD-11/22. October, 2011.

[5]. Carolan, M., Perlman, B., and Tyrell, D. "Alternative Occupied Volume Integrity (OVI) Tests and Analyses." U.S. Department of Transportation, DOT/FRA/ORD13/46, October, 2013.

[6]. Anankitpaiboon, S., Fries, R., and Tunna, L. "Crippling Load Test of Budd Pioneer Car 244, Test 3.” U.S. Department of Transportation, DOT/FRA/ORD-13/23, April, 2013.

[7]. Carolan, M., Perlman, B., and Tyrell, D., "Crippling Test of a Budd Pioneer Passenger Car," American Society of Mechanical Engineers, Paper No. JRC2012-74087, April 2012.

[8]. Carolan, M., Muhlanger, M., Perlman, A.B., Tyrell, D.C., "Occupied Volume Integrity Testing: Elastic Test Results and Analyses," American Society of Mechanical Engineers, Paper No RTD2011-67010, September 2011.

[9]. Carolan, M., Muhlanger, M., "Update on Alternative Occupant Volume Testing," American Society of Mechanical Engineers, Paper No. JRC2010-36020, April 2010.

[10]. Tyrell, D., Jacobsen, K., Martinez, E., and Perlman, A.B. "A Train-to-Train Impact Test of Crash Energy Management Passenger Rail Equipment: Structural Results.” American Society of Mechanical Engineers, Paper No. IMECE2006-13597, November, 2006. 